\title{
Secondary attack rates of COVID-19 in Norwegian families: a nation-wide register-based study
}

\author{
Kjetil Telle $^{1} \oplus \cdot$ Silje B. Jørgensen ${ }^{1,2} \cdot$ Rannveig Hart $^{1} \cdot$ Margrethe Greve-Isdahl $^{1}$. Oliver Kacelnik ${ }^{1}$
}

Received: 29 March 2021 / Accepted: 6 May 2021 / Published online: 25 May 2021

(c) The Author(s) 2021

\begin{abstract}
To characterize the family index case for detected SARS-CoV-2 and describe testing and secondary attack rates in the family, we used individual-level administrative data of all families and all PCR tests for SARS-CoV-2 in Norway in 2020. All families with at least one parent and one child below the age of 20 who lived at the same address $(\mathrm{N}=662,582)$, where at least one member, i.e. the index case, tested positive for SARS-CoV-2 in 2020, were included. Secondary attack rates (SAR7) were defined as the share of non-index family members with a positive PCR test within 7 days after the date when the index case tested positive. SARs were calculated separately for parent- and child-index cases, and for parent- and child-secondary cases. We identified 7548 families with an index case, comprising 26,991 individuals (12,184 parents, 14,808 children). The index was a parent in $66 \%$ of the cases. Among index children, $42 \%$ were in the age group $17-20$ and only $8 \%$ in the age group 0-6. When the index was a parent, SAR7 was $24 \%$ (95\% CI 24-25), whilst SAR7 was $14 \%$ (95\% CI 13-15) when the index was a child. However, SAR7 was $24 \%$ (95\% CI 20-28) when the index was a child aged 0-6 years and declined with increasing age of the index child. SAR7 from index parent to other parent was 35\% (95\% CI 33-36), and from index child to other children $12 \%$ (95\% CI 11-13). SAR7 from index child aged 0-6 to parents was $27 \%$ (95\% CI 22-33). The percent of non-index family members tested within 7 days after the index case, increased from about $20 \%$ in April to $80 \%$ in December, however, SAR7 stabilized at about $20 \%$ from May. We conclude that parents and older children are most often index cases for SARS-CoV-2 in families in Norway, while parents and young children more often transmit the virus within the family. This study suggests that whilst the absolute infection numbers are low for young children because of their low introduction rate, when infected, young children and parents transmit the virus to the same extent within the family.
\end{abstract}

Keywords Transmission in family $\cdot$ Transmission from children $\cdot$ Secondary attack rate $\cdot$ COVID-19 $\cdot$ SARS-COV-2

\section{Introduction}

Despite a recent surge in studies of transmission of SARSCoV-2 in families [1-4], previously reported transmission rates vary widely. Estimates of transmission from children to other family members are particularly scarce $[3,5]$ due to less testing and consequently low numbers of confirmed cases, and possibly more asymptomatic infections in children [6]. One prospective study from the USA found secondary attack rates of over $50 \%$, also from children below

Kjetil Telle

kjte@fhi.no

1 Cluster for Health Services Research, Norwegian Institute of Public Health, Box 222, NO-0213 Skoyen, Oslo, Norway

2 Akershus University Hospital, Nordbyhagen, Lørenskog, Norway
12 years of age, but this study included just 5 index cases in this age group [5]. Viner et al. conclude their systematic review by underlining the particular need for studies "that investigate secondary infections from child or adolescent index cases compared with secondary infections from adult index cases» [7].

Understanding more about the roles of different types of index cases and transmission among family members is vital for containment strategies and contact tracing regimens. More reliable information on transmission from parents and children, both in and outside of the family, is important for decisions on family-wide quarantine measures, mitigation measures in schools and nurseries and limitations of extracurricular activities $[3,7,8]$. Ascertaining the role of index case characteristics in transmission of SARS-CoV-2 to other family members, has been difficult in previous studies because testing strategies have varied, and the number of 
families included has been limited. We provide a populationwide study of the testing and secondary infection rates for all affected families in Norway.

During 2020 about $1 \%(n=50,138)$ of the Norwegian population of 5.4 million was confirmed infected with SARS-CoV-2 by polymerase chain reaction (PCR) tests, and more than 3 million were tested [9]. A trough in new infections in the summer, accompanied by many of the strict containment measures being loosened, was followed by a second peak in late autumn. During the first wave, testing capacity was limited, but there was still comprehensive testing of symptomatic patients and healthcare personnel. During the second wave, testing has been easily accessible and free for anyone with symptoms, as well as all close contacts of confirmed cases. All results from PCR tests for SARS-CoV-2 are transferred automatically and electronically to a national administrative system. This information can be combined with other information about individuals by merging registers based on unique personal identification numbers. These rich and population-wide data provide unique opportunities to improve our understanding of testing behavior and secondary attack rates (SAR) within all affected families by characteristics of family members.

The objective of this study was to describe characteristics of the index case and how testing behavior and SAR in the family varied with these characteristics.

\section{Methods}

\section{Data}

As part of the legally mandated responsibilities of The Norwegian Institute of Public Health (NIPH) during epidemics, a population-wide emergency preparedness register (BeredtC19) was established in cooperation with the Norwegian Directorate of Health [10]. The purpose of the preparedness register is to provide a rapid overview and knowledge of how the pandemic and the measures that are implemented to contain the spread of the virus, affect the population's health, use of healthcare services and healthrelated behaviors.

All laboratories in Norway conducting PCR tests for SARS-CoV-2 send information electronically to the Norwegian Surveillance System for Communicable Diseases (MSIS) when completing a test. Relying on the unique personal identification number provided to every resident in Norway at birth or upon immigration, test results can be linked at the individual level to demographic information in BeredtC19 from the Norwegian Population Registry.

We utilized the individual-level data in BeredtC19 for all residents of Norway, with vital demographic statistics (sex, year of birth, personal identification number of family members), and PCR test results for SARS-CoV-2 (test date, test result). Data on non-positive tests should be interpreted with caution prior to April 2020, as some laboratories did not report all non-positive tests before April.

\section{Population}

Our study population included all members of families with at least one parent and one child aged 0-20 years residing on the same address on March 1st 2020. We included families where at least one person was infected with SARSCoV-2 according to a PCR test taken between March 1st 2020 and January 1st 2021. The data source did not contain non-residents (like tourists, temporary workers and asylum applicants).

\section{Definitions}

Within each family, the index case was defined as the first family member who tested positive. Secondary cases included all non-index family members who tested positive by PCR within 7 days after the testing date of the index case (follow up period to January 31st 2021). We also recorded all non-index family members who were tested by PCR, regardless of test result, within 7 days after the testing date of the index case. Families where one unique index family member could not be identified, as more than one tested positive on the same date, were excluded.

In accordance with other studies, we calculated the proportion of secondary cases by the equation [number of family members with a positive test/number of family members] $\times 100$, excluding the index case in both the numerator and denominator, and focusing on tests undertaken within 7 days of the testing date of the index case [5, 11]. We referred to this proportion as secondary attack rate within 7 days (SAR7). In a supplement, we also provided the proportion within 14 days (SAR14), as well as a plot of the proportion for each day up to 30 days after index testing date.

\section{Analyses}

Descriptive statistics for the families were provided, including number of parents and children. The index case was described with respect to family position (parent, child, mother, father, son, daughter) and age $(\leq 6,7-12,13-16$, $17-20$ years for children, and $\leq 30,31-40,41-50, \geq 50$ years for parents). The overall percentage of non-index family members who were tested by 7 days was calculated, and so was overall SAR7. Both the percentage tested and SAR7s were provided by characteristics of the index. We also calculated separately SAR7s from index child to parents, and from index parent to children. 95\% confidence intervals (95\% CI) around the SARs and percent tested were calculated using 
Table 1 Characteristics of family members of all families in Norway with at least one child and one parent, in which at least one family member tested positive for SARS-CoV-2 in a PCR test in 2020

\begin{tabular}{|c|c|c|c|}
\hline & $\begin{array}{l}\text { All } \\
(\mathrm{N}=26,991)\end{array}$ & $\begin{array}{l}\text { Index } \\
(\mathrm{N}=7548)\end{array}$ & $\begin{array}{l}\text { Non-index } \\
(\mathrm{N}=19,443)\end{array}$ \\
\hline Parents & 12,184 & 4964 & 7219 \\
\hline \multicolumn{4}{|l|}{ Sex } \\
\hline Mother & 7145 & 3083 & 4062 \\
\hline Father & 5038 & 1881 & 3157 \\
\hline \multicolumn{4}{|c|}{ Age groups (years) } \\
\hline$\leq 30$ & 747 & 458 & 289 \\
\hline $31-40$ & 3612 & 1767 & 1845 \\
\hline $41-50$ & 5221 & 1894 & 3327 \\
\hline$\geq 50$ & 2603 & 845 & 1758 \\
\hline Children & 14,808 & 2584 & 12,224 \\
\hline \multicolumn{4}{|l|}{ Sex } \\
\hline Daughter & 7226 & 1298 & 5928 \\
\hline Son & 7582 & 1286 & 6296 \\
\hline \multicolumn{4}{|l|}{ Age groups } \\
\hline$\leq 6$ & 3631 & 200 & 3431 \\
\hline $7-12$ & 4352 & 517 & 3835 \\
\hline $13-16$ & 3575 & 781 & 2794 \\
\hline $17-20$ & 3250 & 1086 & 2164 \\
\hline \multicolumn{4}{|c|}{ Members in family } \\
\hline 2 & 2854 & 1427 & 1427 \\
\hline 3 & 7047 & 2349 & 4698 \\
\hline 4 & 9412 & 2353 & 7059 \\
\hline 5 & 5256 & 1043 & 4213 \\
\hline 6 or more & 2422 & 376 & 2046 \\
\hline
\end{tabular}

the Wilson method. The statistical software used was Stata MP v.16.

\section{Results}

Among all Norwegian families with at least one parent and one child below the age of 20 and living at the same address as of March 1st $2020(\mathrm{~N}=662,582)$, we identified a total of 7548 index cases with confirmed SARS-CoV-2 in 2020. The 7548 families of the index cases comprised 26,991 individuals, of which 12,184 parents (45\%) and $14,808(55 \%)$ children (Table 1).

Among the 7548 index cases, there were 4964 parents $(66 \%)$ and 2584 children $(34 \%)$. There were more mothers (7145) than fathers (5038) in the families, and also among the index persons (3038 vs. 1881). Among adults, the largest age group was $41-50$ years, both in terms of total family members (5221) and index persons (1894). The youngest age group of adults (30 years and below) was the smallest with 747 persons, but had the largest proportion of index cases. Among the 14,808 children, the age groups were of relatively even size, but the number of index cases increased steeply with age, from 200 ( $8 \%$ of child index cases) among the youngest (aged 0-6) to 1086 (42\% of child index cases) among the oldest (aged 17-20). ${ }^{1}$

Both the proportion of tested family members and SAR increased steeply in the first days after the test date of the index case, and the additional increase was modest after 7 days and levelled off after 10 days (Supplement Figure A). The overall SAR7 was $21 \%$, with $95 \%$ CI 20-21 (Table 2). When a parent was the index, SAR7 was $24 \%(95 \% \mathrm{CI}$ 24-25), compared to $14 \%(95 \%$ CI 13-15) when a child was the index.

SAR7 was $24 \%$ (95\% CI 20-28) when the index was a child aged $0-6$, but only $14 \%$ when the index was a child aged 7-12 or 13-16. The lowest SAR7 (11\%, 95\% CI 10-13) was found when a child aged 17-20 was the index. SAR7s were comparable for daughters $(13 \%, 95 \%$ CI 12-14) and sons $(15 \%, 95 \%$ CI 14-16) as index cases. SAR7s were slightly higher when the father was the index $(26 \%, 95 \%$ CI 25-27) than when the mother was the index $(23 \%, 95 \%$ CI 23-24).

SAR7 was $25 \%$ (95\% CI 23-27) when there were six or more members in the family of the index case, and in the range 20-22 for families with 3-5 members. Families with two members had the lowest SAR at 15\% (95\% CI 13-17).

The highest SAR7 is found between adults (parents). SAR7 to parents was higher if a parent was the index case (35\%, 95\% CI 33-36) than if a child was the index case (15\%, 95\% CI 14-16) (Table 2, second column). For SAR7 to children, we saw the same tendency albeit weaker: SAR7 was $21 \%$ (95\% CI 20-22) if a parent was the index case, and $12 \%$ (95\% CI 11-13) if a child was the index case (Table 2, third column). There was more transmission to siblings if the index was in the youngest age group.

Testing rates within 7 days were lower when the index was a parent $(65 \%, 95 \%$ CI 64-66) than when the index was a child (78\%, 95\% CI 77-79) (Table 2, fourth column). When the index case was a child, testing rates declined with the child's increasing age, from $89 \%$ (95\% CI 86-92) when the index was 0-6 years to 66\% (95\% CI 65-67) when the index was aged 17-20. When the index was a parent, testing rates were lowest when the parent was in one of the two lowest age groups ( $56 \%$ for $\leq 30,62 \%$ for $31-40)$ and highest when the parent was in one of the oldest age group (78\% for $\geq 50$ ). The sex of the index person (for both children and adults) did not affect testing rates.

\footnotetext{
${ }^{1}$ Except from an increase in adolescents among the index cases in the summer of 2020, we did not observe substantial changes in the age composition of index parents and children from May to December. Before May, the index cases were predominantly older adults (results not reported).
} 
Table 2 Secondary PCR confirmed SARS-CoV-2 infections in non-index family members within 7 days after index sampling date (SAR7)

\begin{tabular}{|c|c|c|c|c|c|c|c|c|}
\hline \multirow{2}{*}{$\begin{array}{l}\text { Characteristics of } \\
\text { the index case }\end{array}$} & \multicolumn{2}{|l|}{ Overall } & \multicolumn{2}{|c|}{ Among parents } & \multicolumn{2}{|c|}{ Among children } & \multicolumn{2}{|c|}{ Family members tested } \\
\hline & SAR7 & $\begin{array}{l}\text { Numerator/ } \\
\text { denominator }\end{array}$ & SAR7 & $\begin{array}{l}\text { Numerator/ } \\
\text { denomina- } \\
\text { tor }\end{array}$ & SAR7 & $\begin{array}{l}\text { Numerator/ } \\
\text { denominator }\end{array}$ & Rate & $\begin{array}{l}\text { Numerator/ } \\
\text { denominator }\end{array}$ \\
\hline Overall & $21(20-21)$ & $4030 / 19,443$ & $24(23-25)$ & $1723 / 7219$ & $19(18-20)$ & $2307 / 12,224$ & $69(69-70)$ & $13,477 / 19,443$ \\
\hline Parents & $24(24-25)$ & $3102 / 12,695$ & $35(33-36)$ & $1113 / 3196$ & $21(20-22)$ & $1989 / 9499$ & $65(64-66)$ & $8215 / 12,695$ \\
\hline Mother & $23(23-24)$ & $1705 / 7266$ & $33(30-35)$ & $506 / 1543$ & $21(20-22)$ & $1199 / 5723$ & $65(63-66)$ & $4688 / 7266$ \\
\hline Father & $26(25-27)$ & $1397 / 5429$ & $37(34-39)$ & $607 / 1653$ & $21(20-22)$ & $790 / 3776$ & $65(64-66)$ & $3527 / 5429$ \\
\hline \multicolumn{9}{|l|}{$\begin{array}{l}\text { Age groups } \\
\text { (years) }\end{array}$} \\
\hline$\leq 30$ & $17(15-20)$ & $152 / 888$ & $34(28-41)$ & $66 / 192$ & $12(10-15)$ & $86 / 696$ & $56(53-59)$ & $497 / 888$ \\
\hline $31-40$ & $22(20-23)$ & $1011 / 4702$ & $32(29-35)$ & $352 / 1094$ & $18(17-20)$ & $659 / 3608$ & $62(60-63)$ & $2894 / 4702$ \\
\hline $41-50$ & $26(25-28)$ & $1357 / 5161$ & $36(33-39)$ & $467 / 1301$ & $23(22-24)$ & $890 / 3860$ & $69(67-70)$ & $3544 / 5161$ \\
\hline$\geq 50$ & $30(28-32)$ & $582 / 1944$ & $37(34-41)$ & $228 / 609$ & $27(24-29)$ & $354 / 1335$ & $66(64-68)$ & $1280 / 1944$ \\
\hline Children & $14(13-15)$ & $928 / 6748$ & $15(14-16)$ & $610 / 4023$ & $12(11-13)$ & $318 / 2725$ & $78(77-79)$ & $5262 / 6748$ \\
\hline Daughter & $13(12-14)$ & $436 / 3406$ & $14(12-15)$ & $280 / 2025$ & $11(10-13)$ & $156 / 1381$ & $78(77-79)$ & $2659 / 3406$ \\
\hline Son & $15(14-16)$ & $492 / 3342$ & $17(15-18)$ & $330 / 1998$ & $12(10-14)$ & $162 / 1344$ & $78(76-79)$ & $2603 / 3342$ \\
\hline \multicolumn{9}{|l|}{$\begin{array}{l}\text { Age groups } \\
\text { (years) }\end{array}$} \\
\hline$\leq 6$ & $24(20-28)$ & $116 / 487$ & $27(22-33)$ & $79 / 290$ & $19(14-25)$ & $37 / 197$ & $89(86-92)$ & $435 / 487$ \\
\hline $7-12$ & $14(12-15)$ & $198 / 1455$ & $18(15-20)$ & $141 / 803$ & $9(7-11)$ & $57 / 652$ & $86(84-87)$ & $1246 / 1455$ \\
\hline $13-16$ & $14(13-16)$ & $304 / 2109$ & $16(14-18)$ & $191 / 1198$ & $12(10-15)$ & $113 / 911$ & $85(83-86)$ & $1790 / 2109$ \\
\hline $17-20$ & $11(10-13)$ & $310 / 2697$ & $11(10-13)$ & $199 / 1732$ & $12(10-14)$ & $111 / 965$ & $66(65-68)$ & $1791 / 2697$ \\
\hline \multicolumn{9}{|l|}{$\begin{array}{l}\text { Members in } \\
\text { family }\end{array}$} \\
\hline 2 & $15(13-17)$ & $214 / 1427$ & $12(10-15)$ & $59 / 484$ & $16(14-19)$ & $155 / 943$ & $64(61-66)$ & $907 / 1427$ \\
\hline 3 & $22(20-23)$ & $1011 / 4698$ & $25(23-27)$ & $528 / 2098$ & $19(17-20)$ & $483 / 2600$ & $68(67-70)$ & $3217 / 4698$ \\
\hline 4 & $20(19-21)$ & $1393 / 7059$ & $24(22-25)$ & $663 / 2820$ & $17(16-18)$ & $730 / 4239$ & $71(70-72)$ & $5011 / 7059$ \\
\hline 5 & $21(19-22)$ & $832 / 4044$ & $25(23-27)$ & $321 / 1290$ & $19(17-20)$ & $511 / 2754$ & $71(69-72)$ & $2852 / 4044$ \\
\hline 6 or more & $25(23-27)$ & $379 / 1510$ & $27(23-32)$ & $105 / 387$ & $24(22-27)$ & $274 / 1123$ & 66 (64-69) & $1000 / 1510$ \\
\hline
\end{tabular}

The data include all families in Norway consisting of at least one parent and one child, with at least one family member positive for SARSCoV-2 in a PCR test in 2020. Percent (95\% CI) and absolute numbers

Secondary attack rate (SAR7) was calculated as the number of non-index family members who tested positive within 7 days after the date when the index family member tested positive, divided by all non-index family members, multiplied by 100 . Percentage tested was calculated as the number of non-index family members who were tested within 7 days after the date when the index family member tested positive, divided by all non-index family members. 95\% CIs around the estimated secondary infection rates and percentage tested were calculated using the Wilson method

The percent of the non-index family members who were tested within 7 days after the index case, grew from about $20 \%$ in April to about $80 \%$ in December (Fig. 1). The associated SAR7 grew with the proportion of family members tested, up to when testing reached about 50\% in May, after which the SAR7 remained relatively stable, around $20 \%$, despite the testing proportion growing to $80 \%$. Thus, restricting the analysis to the period with increased testing capacity (July 1st - December 31st 2020) yields slightly higher SARs, but main results remain the same (compare Table 2 and Supplement Table B).

\section{Discussion}

In this nation-wide register study, we used SARS-CoV-2 PCR test results from all public and private Norwegian laboratories during 2020, combined with administrative population register data that identified all family members (parents and children) living at the same address. 
Fig. 1 Monthly variation in secondary PCR confirmed SARS-CoV-2 infections in nonindex family members by 7 days after the date when index family member was positive (SAR7), and analogously for rate of non-index family members who were tested by 7 days (Tested). All families in Norway with at least one parent and one child, where at least one family member tested positive for SARSCoV-2 in a PCR test in 2020

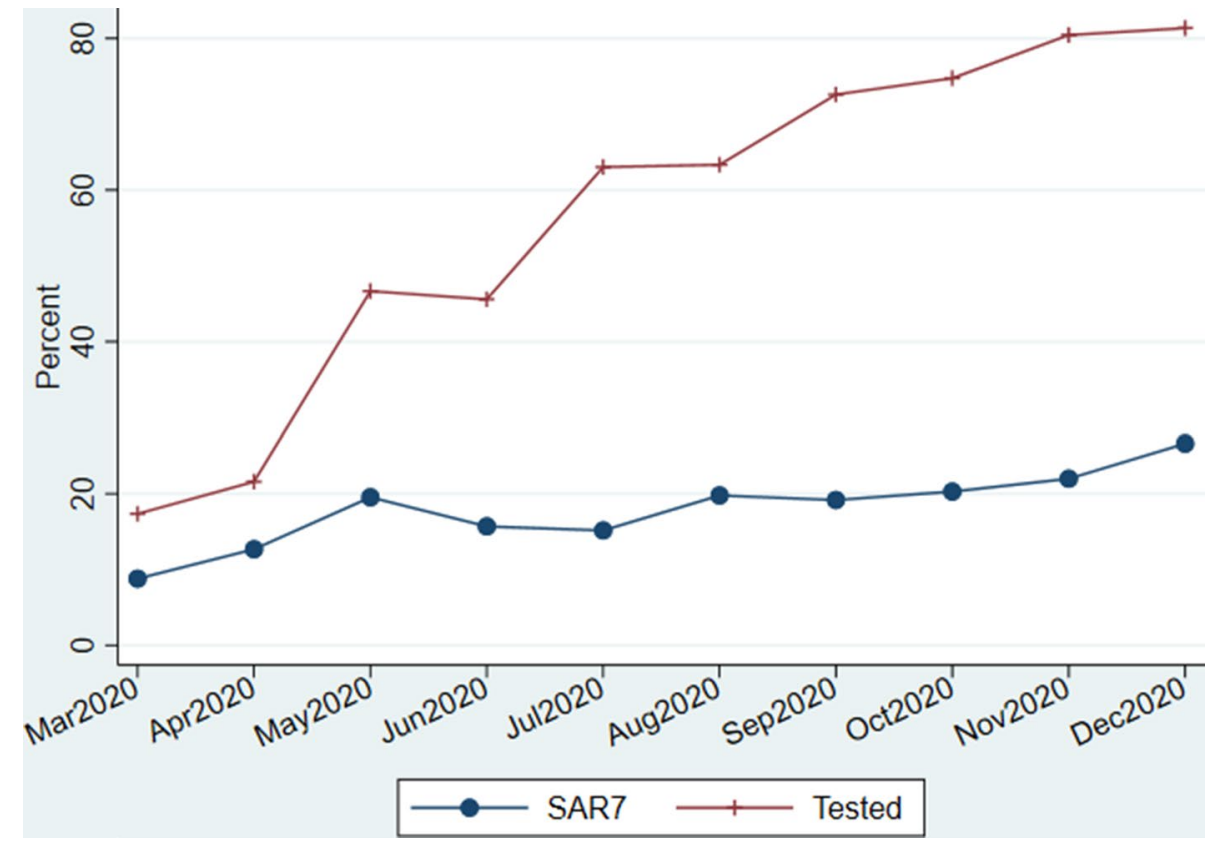

\section{Principal findings}

The index cases are mainly the parents (66\%), even though there are fewer parents than children in the families. The children aged $17-20$ years comprise $22 \%$ of all the children, but as many as $42 \%$ of the child index cases. The younger children are not often the index case. This could be because they display less symptoms, because it is easier to test an adult than a small child if both have symptoms, or because small children are less often infected outside of the family. This distribution of index cases in the families does not fully reflect the age-distribution of infected residents of Norway in 2020 , where 6629 of those below 20 ( $0.5 \%$ of residents in the age group) and 18,643 of those aged $20-50(0.9 \%)$ had been infected. This suggests that the overrepresentation of parents as index in the family group (66\%) is lower than for adults $20-50$ in the population at large (74\%), possibly reflecting both different infection rates in adults living in families with children compared with adults living in families without children or alone, and higher SARs between parents within the family.

Subsequent transmissions within the families follow different patterns depending on the age of the index case. SAR7 was high both when a parent was the index $(24 \%, 95 \%$ CI 24-25) and when a young child aged 0-6 was index (24\%, 95\% CI 20-28). However, it was low when an older child aged $17-20$ was the index $(11 \%, 95 \%$ CI $10-13)$. In short, parents and older children contribute the most to the introduction of SARS-CoV-2 into the family, while parents and young children contribute the most to transmitting the disease within the family. It could be that older children more often have another residence than the one they are registered at, i.e. in student accommodation or due to shared custody between parents. However, older children may also behave in ways that restrict viral transfer more than young children.

Parents transmit to other parents $(35 \%, 95 \%$ CI 33-36) and less to children $(21 \%, 95 \%$ CI $20-22)$, while children transmit similarly to parents $(15 \%, 95 \%$ CI $14-16)$ and other children (12\%, 95\% CI 11-13).

Most cases of household transmission are detected by day 7 after the index tested positive (SAR7 21\%), increasing only somewhat to day 14 (SAR14 24\%). In this study, the share of the non-index family members who had been tested was $69 \%$ (95\% CI 69-70) by day 7, increasing to $72 \%$ (95\% CI 72-73) by day 14 .

The percent of the non-index family members who were tested within 7 days was low in March and April (20\%), but increased to 50\% in May and to above $80 \%$ in December (Fig. 1). While SAR7 grew in parallel with the percent tested from March to May, when testing rates grew beyond $50 \%$ from May, SAR7 remained around 20\%. Supplement Tables B and C show that our results (Table 2) do not change much if we restrict the analysis to the period with increased testing (i.e. from July 1 st to December 31st 2020, instead of whole 2020).

\section{Comparison with related studies}

Previous literature on intra-family transmission of SARSCoV-2 is inconclusive, as the studies are few and small, with different designs, and report widely varying SARs $[1-7$, 11-13].

We observed an overall SAR in line with previous studies, e.g. in two systematic reviews Madewell et al. reported 
household SAR of 17\% [1] and Lei et al. of 27\% [12], both suggesting lower SARs to children than to adults. Viner et al. also estimate lower SAR from children than adults [7]. However, comparison across studies is hard due to varying follow-up times, unclear handling of co-index cases, different testing regimes and small samples, especially for young child index cases. Very few studies calculate SARs across characteristics of the index or separately to parents and children. Grijalva et al. is a notable exception, but they only have five index children below the age of 12 [5]. Viner et al. find that their data were insufficient to conclude whether transmission of SARS-CoV-2 by children is lower than by adults, and they conclude their review by stating that studies "that investigate secondary infections from child or adolescent index cases compared with secondary infections from adult index cases are particularly needed» [7].

\section{Interpretations}

Norway has based much of its pandemic response on a demanding strategy of coordinated application of testing everyone with minor symptoms, isolation of positive cases, careful tracing of probable contacts and quarantine through the incubation period. The indications for testing, definitions of close contacts and length of quarantine have been regulated by law and adjusted over the course of the pandemic.

The observed increase in testing of family members reflects the increasing availability and reliance on testing throughout the pandemic. PCR-testing has been widely available in Norway, though in the first few months of the pandemic only symptomatic cases and healthcare personnel had wide access to the tests. From May and onwards, however, anyone wanting a test could get one by contacting their local municipal test-station, where testing was free of charge. This resulted in intensive testing as the infection rate started to grow from August, increasing the probability of persons with few or no symptoms to be included as index cases, and increasing the probability of secondary cases to be identified. It is worth noting that the frequency of testing for children, whilst generally lower than for the whole population, has been relatively high in relation to outbreaks in schools and nurseries.

Our study found that the recorded SAR7 was nearly as high as the SAR14. Almost all detected intra-family transmission occurs within the first 7 days after the detection of an index case. This supports the current Norwegian strategy of testing and quarantine for 7-10 days for all family members after infection within the household.

An aggressive test/quarantine/isolate/-trace strategy can influence SAR and explain some of the variation in SAR in different studies. One would suspect that SAR7 is lower if the index case was tested in the presymptomatic period, as part of a contact tracing regimen, than if the index case was tested after symptom development, when the family would have been exposed for a longer time without prevention measures. We do not know how many of the index cases in our study who had symptoms, or whether they were tested because they were included in contact tracing around another case outside of the family.

We found substantial differences in the SAR depending on the characteristics of both the index case and the family composition. SAR was higher when young children (0-6 years) compared with older children were index, probably reflecting that the youngest need more close contact with their caregivers. Other studies have suggested that children have a lower attack rate and lower predisposition to serious disease and onward spread $[1,3,6,11]$. After the lockdown period in March and April 2020, when the nurseries and schools reopened, strict infection control measures were applied to prevent transmission in these institutions. To which extent these measures have been successful needs to be examined further, but our results underline that children should be kept at home when they have symptoms that could indicate infection, and, moreover, that grandparents and other caregivers in risk groups for severe COVID-19 should not provide childcare for symptomatic children.

When the index case was a parent, there was a higher SAR towards the other parent than towards the children, and the SAR from young children was higher towards their parents than towards their siblings. The lower SAR rate we observe with increasing age of the index child most likely reflects the ability to identify cases earlier due to symptomatology, and also less close contact among the older children and the adults in the house. For very young children, it will likely be difficult to reduce contact even when contagion is detected. We also found a higher SAR associated with older parents than with younger ones. This may be due to a higher level of symptoms, and perhaps a higher level of caution resulting in more testing due to higher risk for serious disease among the oldest parents. However, we do not have data to explore this question.

As could be expected, a priori, we saw an increased SAR associated with the index living with a larger family. This reflects the larger number of contacts and probably more cramped living conditions. Norwegian advice has been that when isolating at home, cases should where possible, have their own bathroom, meals brought to them and as little contact with the rest of the house as possible. This is harder in situations of large families sharing smaller living spaces. Alternative housing has only been offered and accepted to a limited extent. Measures that make alternative housing more appealing, for instance moving the whole household to a larger dwelling rather than splitting out the index, may be considered. 


\section{Potential limitations}

The current Norwegian recommendations are that all close contacts should be tested at least once, preferably twice within a 10-day (recently 7 day) period after the diagnosis of the index. In our study, the proportion of the nonindex family members who had been tested by 7 days after index date, is very high, but not $100 \%$. It is thus possible that asymptomatic cases are sometimes not tested, and there is reason to assume that children below 6 years of age are overrepresented in this group, because they are more difficult to test. This may affect who we identify as index cases, and maybe also which secondary cases are identified. For example, when a young child (0-6) was index, about $90 \%$ of the family members were tested within 7 days after index date, while this number was about $70 \%$ when a parent was index, which might suggest that more secondary cases were identified when index was a child than when index was a parent.

Better knowledge of actual directions of transmission within families requires prospective studies where all family members are tested daily with the same method in the week following index identification, preferably also with reporting of symptoms and genome identification of the viruses. Genome analysis would also help to reveal exposure to multiple infection events within the same family, which could interfere with the detected SAR. However, the incidence rate of SARS-CoV-2 has been low in Norway during the pandemic, estimated to peak at 74 per 100,000 per week towards the end of 2020 [9], which makes several transmission incidents into the same family at the same time less likely. A clear advantage of our study to such prospective studies, is that we do not have attrition: We observe every family, and we can observe all family members in the followup period, regardless of motivation to participate in a study or not. Indeed, our data stem from a real-world situation, where detection of secondary cases relates to a combination of the actual transmission of the virus and the behavioral responses to disease and the actual testing regime. This point is illustrated by us seeing lower SAR in the two first months of the pandemic, when testing capacity was limited, than later, when testing of family members was widely available. It seems that a test capacity where about $50 \%$ of the nonindex family members are being tested, results in roughly the same SAR as a test regime where $80 \%$ of the non-index family members are tested. Another way of putting this, is that testing of cases with mild symptoms captures most of the cases. It should also be noted that we intentionally excluded families where there were "co-indexes" that could result in a greater infection pressure within the household.

Another limitation to our study is that the observation period does not include the coldest winter months, where people usually spend more time indoors, and when the climate is more favorable for viral sustainability on surfaces, and maybe also for transmission. Similar factors may also explain some of the variation in SARs between different studies. We observed a small increase in SAR during December 2020, which may be a coincidence, or perhaps due to colder weather or closer contact between family members during the celebration of Christmas. Moreover, the introduction of variants of new and more easily transferable virus mutants could have played a role.

\section{Conclusions}

By looking at register data for all families in Norway we see that parents and older children are most often index cases for SARS-CoV-2 detection. However, after introduction into the family unit, virus transmission within the family is more common from parents and preschool children than from older children. Detected infection rates among young children may be low, but this study suggests that infected young children transmit the virus within the family to the same extent as parents.

Supplementary Information The online version contains supplementary material available at https://doi.org/10.1007/s10654-021-00760-6.

Acknowledgements We would like to thank the Norwegian Directorate of Health, in particular Director for Health Registries Olav Isak Sjøflot and his department, for excellent cooperation in establishing the emergency preparedness register. We would also like to thank Gutorm Høgåsen and Anja Elsrud Schou Lindman for their invaluable efforts in the work on the register. We are grateful to Elisabeth Astrup, Ingeborg Elgersma, Tone B. Johansen and Karin Nygård for providing helpful comments to an earlier version of the manuscript. All interpretations and reporting of the data are the sole responsibility of the authors, and no endorsement by the register is intended or should be inferred. We would also like to thank everyone at the Norwegian Institute of Public Health who has been part of the outbreak investigation and response team.

Author contributions KT designed the study and had access to all the data in the study and takes full responsibility for the integrity of the data and the accuracy of the statistical analysis. OK and SBJ contributed to and critically evaluated the medical and contextual content of the analysis, and drafted the manuscript with KT. All authors contributed with conceptual design, analyses and interpretation of results. All authors contributed by critically revising the article for important intellectual content. All authors gave final approval for the version to be submitted.

Funding Open access funding provided by Norwegian Institute of Public Health (FHI). No external funding was received.

Availability of data and materials For confidentiality reasons authors are not allowed to share the data.

Code availability Stata16-code available upon request. 


\section{Declarations}

Conflict of interest The authors declare that they have no conflict of interest.

Ethical approval The establishment of an emergency preparedness register forms part of the legally mandated responsibilities of NIPH during epidemics. Institutional board review was conducted, and the Ethics Committee of South-East Norway confirmed (June 4th 2020, \#153204) that an external ethical board review was not required. The study was based on deidentified data already available in the preparedness register.

Open Access This article is licensed under a Creative Commons Attribution 4.0 International License, which permits use, sharing, adaptation, distribution and reproduction in any medium or format, as long as you give appropriate credit to the original author(s) and the source, provide a link to the Creative Commons licence, and indicate if changes were made. The images or other third party material in this article are included in the article's Creative Commons licence, unless indicated otherwise in a credit line to the material. If material is not included in the article's Creative Commons licence and your intended use is not permitted by statutory regulation or exceeds the permitted use, you will need to obtain permission directly from the copyright holder. To view a copy of this licence, visit http://creativecommons.org/licenses/by/4.0/.

\section{References}

1. Madewell ZJ, Yang Y, Longini IM Jr, Halloran ME, Dean NE. Household transmission of SARS-CoV-2: a systematic review and meta-analysis. JAMA Netw Open. 2020;3(12):e2031756. https:// doi.org/10.1001/jamanetworkopen.2020.31756.

2. Tian T, Huo X. Secondary attack rates of COVID-19 in diverse contact settings, a meta-analysis. J Infect Dev Ctries. 2020;14:1361-7. https://doi.org/10.3855/jidc.13256.

3. European Centre for Disease Prevention and Control. COVID-19 in children and the role of school settings in transmission - first update. Stockholm; 2020. First update, 23rd December 2020.

4. Kuwelker K, Zhou F, Blomberg B, Lartey S, Brokstad KA, Trieu $\mathrm{MC}$, et al. High attack rates of SARS-CoV-2 infection through household-transmission: a prospective study. medRxiv. 2020. https://doi.org/10.1101/2020.11.02.20224485.
5. Grijalva CG, Rolfes MA, Zhu Y, McLean HQ, Hanson KE, Belongia $\mathrm{E}$, et al. Transmission of SARS-COV-2 infections in households-Tennessee and Wisconsin, April-September 2020. MMWR Morb Mortal Wkly Rep. 2020;69:1631-4. https://doi. org/10.15585/mmwr.mm6944elexternalicon.

6. Kim J, Choe YJ, Lee J, Park YJ, et al. Role of children in household transmission of COVID-19. Arch Dis Child. 2020;. https:// doi.org/10.1136/archdischild-2020-319910.

7. Viner RM, Mytton OT, Bonell C, Melendez-Torres GJ, Ward J, Hudson L, et al. Susceptibility to SARS-CoV-2 infection among children and adolescents compared with adults: a systematic review and meta-analysis. JAMA Pediatr. 2021;175(2):143-56. https://doi.org/10.1001/jamapediatrics.2020.4573. Erratum in: doi: https://doi.org/10.1001/jamapediatrics.2020.4907.

8. Brandal L, Ofitserova T, Meijerink H, Rykkvin R, Lund H, Hungnes $\mathrm{O}$, et al. Minimal transmission of SARS-CoV-2 from paediatric COVID-19 cases in primary schools, Norway, August to November 2020. Eurosurveillance. 2021. https://doi.org/10.2807/ 1560-7917.ES.2020.26.1.2002011.

9. Norwegian Institute of Public Health. Weekly reports of the COVID-19 situation in Norway. Week 1. 2021. https://www.fhi. no/contentassets/8a971e7b0a3c4a06bdbf381ab52e6157/vedlegg/ 2021/ukerapport-for-uke-1-04.01-10.01-2021.pdf.

10. The Norwegian Emergency Preparedness Register (BEREDT C19). 2020. https://www.fhi.no/sv/smittsomme-sykdommer/ corona/norsk-beredskapsregister-for-covid-19/; March 2021.

11. Park Y, Choe Y, Park O, Park S, Kim Y, Kim J, et al. Contact tracing during Coronavirus disease outbreak, South Korea, 2020. Emerg Infect Dis. 2020;26(10):2465-8. https://doi.org/10.3201/ eid2610.201315.

12. Lei $\mathrm{H}, \mathrm{Xu} \mathrm{X}, \mathrm{Xiao} \mathrm{S}, \mathrm{Wu} \mathrm{X}, \mathrm{Shu} \mathrm{Y}$. Household transmission of COVID-19-a systematic review and meta-analysis. J Infect. 2020;81(6):979-97. https://doi.org/10.1016/j.jinf.2020.08.033.

13. Wang Y, Tian H, Zhang L, Zhang M, Guo D, Wu W, et al. Reduction of secondary transmission of SARS-CoV-2 in households by face mask use, disinfection and social distancing: a cohort study in Beijing, China. BMJ Glob Health. 2020. https://doi.org/10.1136/ bmjgh-2020-002794.

Publisher's Note Springer Nature remains neutral with regard to jurisdictional claims in published maps and institutional affiliations. 